\title{
Changes in diet associated greenhouse gas emissions and diet quality of consumers in Scotland between 2007 and 2012
}

\author{
S. Whybrow and J.I. Macdiarmid \\ Rowett Institute, University of Aberdeen, Aberdeen AB25 2ZD.
}

Consumers in Scotland responded to the rapid food price increases between 2007 and 2009 partly by buying less food. Energy from food and drink purchased and brought into the home decreased significantly between 2007 and 2012 , from 8.6 to 8.2 MJ per adult equivalent per day ${ }^{(1)}$. Household food and drink waste has also decreased since $2007^{(2)}$. After accounting for the decrease in food waste, estimated energy intake was not different (7.3 and 7.2 MJ per adult equivalent per day for 2007 and 2012 respectively, $\mathrm{p}=0 \cdot 186)^{(1)}$. Dietary choices in Scotland contribute to it having one of the worst obesity records among developed countries, and are having significant environmental impacts. The aim of the study was to assess the effects of changes in food and drink purchases, and decreases in food waste, between 2007 and 2012 on diet associated greenhouse gas emissions (GHGE) and diet quality, and if changes differed by level of socio-economic status.

Household level food and drink purchases (excluding those consumed outside the home) recorded by Kantar Worldpanel (KWP) were adjusted for waste using factors for the two years, and scaled for household composition, to give values per adult equivalent.

GHGE of each household's food and drink purchases were estimated by linking the 2091 food groups that were defined by KWP for retail purposes, to foods and environmental data ${ }^{(3)}$. A Diet Quality Index (DQI) was calculated, based on the Revised Dietary Goals for Scotland (RDGS), with scoring from 0 (lowest) to 100 (highest). Socio-economic status was measured through the Scottish Index of Multiple Deprivation (SIMD).

\begin{tabular}{|c|c|c|c|c|c|c|c|c|c|}
\hline & \multirow[b]{2}{*}{ Year } & \multicolumn{5}{|c|}{ Quintiles of Scottish Index of Multiple Deprivation } & \multirow[t]{2}{*}{$\begin{array}{c}\mathrm{P} \\
\text { (year) }\end{array}$} & \multirow[t]{2}{*}{$\begin{array}{c}\mathrm{P} \\
(\mathrm{SIMD})\end{array}$} & \multirow[t]{2}{*}{$\begin{array}{c}\mathrm{P} \\
\left(\mathrm{SIMD}^{*} \text { year}\right)\end{array}$} \\
\hline & & 1 (most) & 2 & 3 & 4 & 5 (least) & & & \\
\hline \multirow[t]{2}{*}{ n of households } & 2007 & 440 & 541 & 506 & 527 & 412 & & & \\
\hline & 2012 & 437 & 570 & 566 & 542 & 465 & & & \\
\hline \multirow[t]{2}{*}{ GHGE $^{1}$} & 2007 & 3.4 & $3 \cdot 4$ & $3 \cdot 4$ & $3 \cdot 3$ & $3 \cdot 4$ & $<0 \cdot 001$ & $0 \cdot 451$ & $0 \cdot 525$ \\
\hline & 2012 & $3 \cdot 0$ & $3 \cdot 1$ & $3 \cdot 2$ & $3 \cdot 0$ & $3 \cdot 0$ & & & \\
\hline \multirow[t]{2}{*}{ DQI } & 2007 & $34 \cdot 6$ & $35 \cdot 9$ & $37 \cdot 7$ & $38 \cdot 6$ & $40 \cdot 5$ & 0.005 & $<0.001$ & 0.035 \\
\hline & 2012 & $37 \cdot 2$ & $37 \cdot 5$ & $37 \cdot 5$ & $38 \cdot 8$ & $41 \cdot 3$ & & & \\
\hline
\end{tabular}

${ }^{1} \mathrm{~kg} \mathrm{CO}$ equivalent per adult equivalent per day. Authors' calculations from Kantar Worldpanel data.

Estimated GHGE associated with food and drink purchases decreased between 2007 and 2012. Values per adult equivalent were similar across all areas of SIMD.

Diet quality (by DQI) was far from meeting the RDGS, although it increased slightly between 2007 and 2012 . DQI was lower in households from more deprived areas, but bigger increases were seen between 2007 and 2012 for these households. This was mainly because of decreases in the amounts of red and processed meat purchased. Although households in all quintiles of SIMD bought less red and processed meat in 2012 compared to 2007, there were fewer households from the more deprived areas that met the RDGS for red and processed meat in 2007, giving greater scope for improving this part of the diet. Similarly, \%energy from fat was higher in the more deprived areas in both years, but decreased overall between 2007 and 2012. These small, but statistically significant, changes resulted in an effect of SIMD on change in DQI score between 2007 and 2012.

Changes in the amount and composition of food and drink purchased and brought into the home, and decreases in food waste, between 2007 and 2012 appear to have lowered the GHGE associated with this part of the diet. Diet quality improved slightly over the same period, with bigger improvements in households from the more deprived areas.

1. Whybrow S, Horgan G \& Macdiarmid J (2017) Public Health Nutr 20, 248-1256.

2. WRAP (2013) Household Food and Drink Waste in the United Kingdom 2012. Banbury: Waste and Resources Action Programme.

3. Barilla Center for Food \& Nutrition (2015) Double Pyramid 2015: Recommendations for a Sustainable Diet. Rome: Barilla Center for Food \& Nutrition. 